This is an author produced version of a paper published in Advances in Nano Research.

This paper has been peer-reviewed and includes the final publisher proofcorrections and journal pagination.

Citation for the published paper:

Marion Collart Dutilleul, Gulaim A. Seisenbaeva and Vadim G. Kessler. (2014) Novel solvothermal approach to hydrophilic nanoparticles of late transition elements and its evaluation by nanoparticle tracking analysis. Advances in Nano Research. Volume: 2, Number: 2, pp 77-88.

http://dx.doi.org/10.12989/anr.2014.2.2.077.

Access to the published version may require journal subscription. Published with permission from: Techno-Press.

Epsilon Open Archive http://epsilon.slu.se 


\title{
Novel solvothermal approach to hydrophilic nanoparticles of late transition elements and its evaluation by nanoparticle tracking analysis
}

\author{
Marion Collart Dutilleul ${ }^{1}$, Gulaim A. Seisenbaeva ${ }^{2}$ and Vadim G. Kessler ${ }^{* 2}$ \\ ${ }^{1}$ Ecole National Supériore de Chimie de Clermont Ferrand, 24 Avenue des Landais, 63170 Aubière, France \\ ${ }^{2}$ Department of Chemistry, Biocenter, Swedish University of Agricultural Sciences, \\ Box 7015, SE-75007 Uppsala, Sweden
}

(Received July 17, 2013, Revised March 4, 2014, Accepted March 5, 2014)

\begin{abstract}
Solvothermal treatment of late transition metal acetylacetonates in a novel medium composed either of pure acetophenone or acetophenone mixtures with amino alcohols offers a general approach to uniform hydrophilic metal nanoparticles with high crystallinity and low degree of aggregation. Both pure metal and mixed-metal particles can be accesses by this approach. The produced materials have been characterized by SEM-EDS, TEM, FTIR in the solid state and by Nanoparticle Tracking Analysis in solutions. The chemical mechanisms of the reactions producing nanoparticles has been followed by NMR. Carrying out the process in pure acetophenone produces palladium metal, copper metal with minor impurity of $\mathrm{Cu}_{2} \mathrm{O}$, and $\mathrm{NiO}$. The synthesis starting from the mixtures of $\mathrm{Pd}$ and $\mathrm{Ni}$ acetylacetonates with up to 20 mol\% of Pd, renders in minor yield the palladium-based metal alloy along with nickel oxide as the major phase. Even the synthesis starting from a mixed solution of $\mathrm{Cu}(\mathrm{acac})_{2}$ and $\mathrm{Ni}(\mathrm{acac})_{2}$ produces oxides as major products. The situation is improved when aminoalcohols such as 2-aminoethanol or 2-dimethylamino propanol are added to the synthesis medium. The particles in this case contain metallic elements and pairs of individual metals (not metal alloys) when produced from mixed precursor solutions in this case.
\end{abstract}

Keywords: metal nanoparticle; solvothermal synthesis; solvent effect; beta-hydrogen transfer; solution stability

\section{Introduction}

Nanoparticles of late transition elements attracted during the recent years increased attention of researchers in the view of their extremely broad application domains covering such different areas as plasmonics (Shaadt 2005), photocatalysis (Füldner 2010) and photoelectrochemical water decomposition for artificial photosynthesis and hydrogen gas production (Chen 2010), and the chemical catalysis in both oxidation (Roucoux 2002) and reduction (Roucoux 2002, Narayanan 2005, Crooks 2001) processes related, in particular, to refinement and upgrading of biofuels. A matter of special focus have been bimetallic and especially core-shell metal nanostructures, where the aims have been to create magnetic noble metal particles for biomedical application (Kowlgi

*Corresponding author, Professor, E-mail: vadim.kessler@slu.se 
2011), on one hand, and lower the cost of a noble metal catalyst on the other (Moreno-Mañas 2003).

A plethora of synthetic approaches to late transition metal nanoparticles has been developed through the recent years, involving reduction of metal salts by strong reducing agents such as sodium tetrahydroborate (Qi 1997, Hou 2005, Aparna 2005, ) or the thermal decomposition of, primarily, carbonyl precursors (Robinson and Zacchini 2009, Robinson and Volk 2009). These approaches suffer generally from the need to apply surfactants in both aqueous and non-aqueous media to avoid aggregation and to control the particle size (Hou 2005), and from the need to use highly toxic precursors such as carbonyls (Robinson and Zacchini 2009, Robinson and Volk 2009), or the need in special equipment such as for autoclave synthesis under supercritical conditions (Shin 2010).

Bradley reaction, the solvothermal decomposition of metal alkoxides and alcohol solvates of salts at low temperatures through ether elimination and beta-hydrogen elimination has been reported recently as a route to highly crystalline oxide nanoparticles of a broad variety of compositions (Pazik 2009, Pazik 2013), involving in particular late transition metals. Even the synthesis of highly uniform in size palladium nanoparticles by this approach in acetophenone as solvent has been demonstrated (Wilkinson 2011). Best crystallinity in the synthesis by Bradley reaction is achieved when high-boiling point aprotic solvent such as, for example, acetophenone, is used as reaction medium. Different chemical mechanisms, producing oxides from metal-organic precursors involve crotonic condensation of the solvent (Scheme 1):

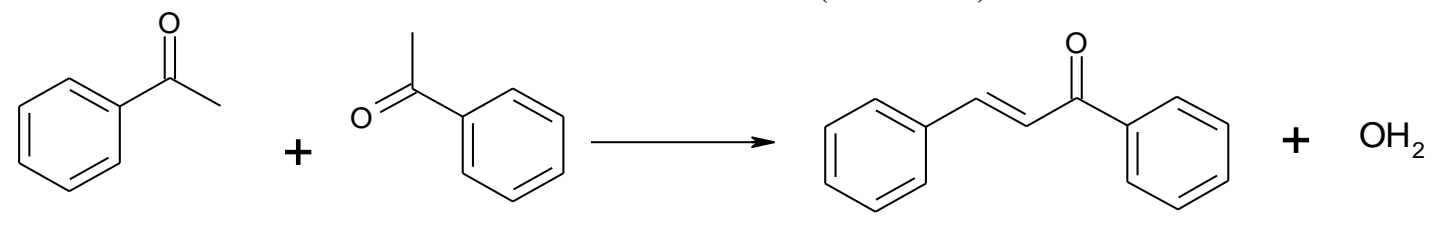

Scheme 1 Crotonic condensation of acetophenone

The most probable pathway involving participation of metal alkoxides proceeds through formation of ketal derivatives (Scheme 2):

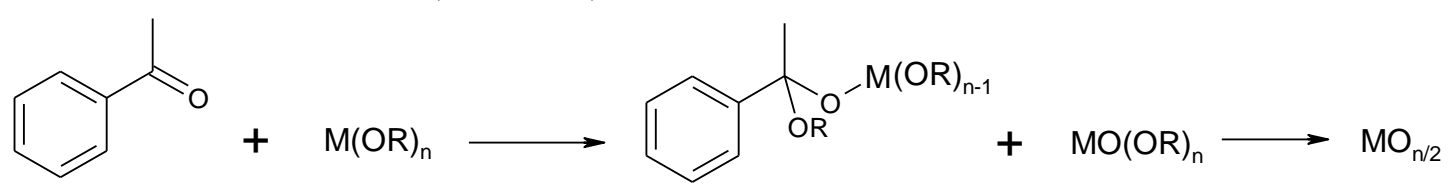

Scheme 2 Condensation with formation of ketal derivatives

Last, but not the least, with the transition metal cations possessing oxidative properties, and the alkoxide ligands, especially the secondary ones such as ${ }^{\mathrm{i}} \mathrm{PrOH}$ and $\mathrm{R}^{\mathrm{N}} \mathrm{OH}$ (2-aminopropanol) and even with the derivatives of enols, such as acetylacetonates, the process occurs as oxidation via a different mechanism [3] - the so-called $\beta$-hydrogen elimination, reducing these metal centers (Scheme 3):

$$
\begin{aligned}
& \mathrm{M}\left(\mathrm{O}^{\mathrm{i}} \mathrm{Pr}\right)_{\mathrm{n}} \quad \rightarrow \quad \mathrm{M}\left(\mathrm{O}^{\mathrm{i}} \mathrm{Pr}\right)_{\mathrm{n}-1} \mathrm{H}+\mathrm{CH}_{3} \mathrm{COCH}_{3} \\
& \mathrm{M}\left(\mathrm{O}^{\mathrm{i}} \mathrm{Pr}\right)_{\mathrm{n}-1} \mathrm{H} \quad \rightarrow \quad \mathrm{M}\left(\mathrm{O}^{\mathrm{i}} \mathrm{Pr}\right)_{\mathrm{n}-2}+\mathrm{HO}^{\mathrm{i}} \mathrm{Pr}
\end{aligned}
$$

For late transition metal cations such as $\mathrm{Ni}^{2+}, \mathrm{Cu}^{2+}, \mathrm{Pd}^{2+}$ and $\mathrm{Pt}^{2+}\left(\right.$ most probably even $\mathrm{Co}^{2+}$ ) this 2 -electron reduction could be expected to result in formation of completely reduced metals (in the form of nanoparticles).

In the present article we report the application of this solvothermal approach to the preparation 
of spherical $\mathrm{Ni}, \mathrm{Cu}, \mathrm{Ni}-\mathrm{Pd}$ and $\mathrm{Ni}-\mathrm{Cu}$ nanoparticles of well-defined size and low degree of aggregation in the absence of surfactants. The latter has been tested directly after synthesis by the

Nanoparticle Tracking Analysis (NTA). The NTA is a new and strong tool to investigate the size of nanoparticles and their aggregation (Filipe 2010). This technique exploits Brownian motion of the individual particles to obtain the information about their size. The dispersion of particles is put under an ultramicroscope and the image is analyzed following the movement of each individual laser beam reflection, disclosing the motion of an individual nanoparticle. The speed of this motion stays in relation to the size of the particle and the viscosity of the solvent. The hydrodynamic radius of the particle is calculated using these parameters together with the density of the material the particles are composed of. An important additional feature is that the image analysis permits even to evaluate the relative intensity of each individual spot, thus revealing potentially different phases present in the sample. We have recently successfully applied this technique for characterization of aggregation of metal oxide nanoparticles (Pazik and Seisenbaeva 2011) and even for the investigation of this process in real time (Nikonova 2011).

\section{Experimental}

All the operations with precursors and solvents used in this work were carried out in ambient atmosphere. The chemicals, $\mathrm{Ni}(\mathrm{acac})_{2}, \mathrm{Cu}(\mathrm{acac})_{2}, \mathrm{Pd}(\mathrm{acac})_{2}$, acetophenone, 2-dimethylamino propanol, 2-dimethylamino ethanomand 2-aminoethanol were purchased from Aldrich and used as received. Ethanol (99.5\%) was received from Solveco AB, Sweden. Ni(II) 2-dimethylamino propoxide was obtained through interaction of $\mathrm{Ni}\left(\mathrm{NH}_{3}\right)_{6} \mathrm{Cl}_{2}$ with $\mathrm{NaCH}\left(\mathrm{CH}_{3}\right) \mathrm{CH}_{2} \mathrm{~N}_{(}\left(\mathrm{CH}_{3}\right)_{2}$ as described earlier by Werndrup (2001).

The typical synthetic procedures involved heating of precursor solutions under reflux in $4 \mathrm{~h}$. For the synthesis in pure acetophenone about $0.3 \mathrm{~g}$ of a precursor or a mixture of precursors in a given molar ratio was subjected to reflux. The synthesis resulted normally in a minor amount of precipitate and a colloid solution of nanoparticles that were separated by centrifugation, washed 3 times with $10 \mathrm{~mL}$ of ethanol and ether dried in vacuum for further characterization or re-dispersed in $10 \mathrm{~mL}$ ethanol by sonication in $10 \mathrm{~min}$ (for further studies of aggregation or preparation of TEM samples). When aminoalcohols were used as reducing agents there amount was calculated as 2 mol. equivalent per mol of the late transition metal.

The SEM-EDS investigation of the samples was carried with Hitachi TM-1000- $\mu$-DeX microscope and the TEM studies with the Philips EM400 microscope at the Swedish Veterinary Medicine Institute. The X-ray diffraction patterns were registered using Apex-II multipurpose diffractometer operating at MoK $\alpha$ radiation. The FTIR spectra were registered using the PerkinElmer Spectrum 100 instrument. The NMR studies $\left({ }^{1} \mathrm{H},{ }^{13} \mathrm{C}\right)$ were carried out for the vacuum distilled fractions obtained from mother liquors from synthesis with Avance Bruker $600 \mathrm{MHz}$ instrument. The analysis of particle aggregation in the ethanol solution was made by Nanoparticle Tracking Analysis technique using NanoSight instrument calibrated with a standard set of polystyrene microspheres.

\section{Results and discussion}

\subsection{NTA and TEM analysis of the synthesis products}


We have chosen the Bradley reaction in acetophenone as solvent in the view of its ability to deliver non-aggregated nanoparticles. This results from easy nucleation of both oxides (Pazik 2009) and noble metal particles (Wilkinson 2011) emerging in the form of single crystals of the corresponding phase. It has been thus observed that among the late transition metals the solvothermal synthesis starting from $\mathrm{Ni}(\mathrm{acac})_{2}$ yields in the absence of reducing agents solely $\mathrm{Ni}(\mathrm{II})$ derivatives (Pazik 2013), while $\mathrm{Pd}(\mathrm{acac})_{2}$ produces the reduced phase of $\mathrm{Pd}(\mathrm{s})$, the so called H-Pd (Wilkinson 2011). Subsequent growth should be possible for beta-diketonate precursor case and non-noble metals or metal oxides due to Ostwald ripening. The particles produced by reflux in acetophenone from solutions of $\mathrm{Cu}(\mathrm{acac})_{2}, \mathrm{Ni}(\mathrm{acac})_{2}$, and mixed solutions of those two as well as mixed solutions of $\mathrm{Ni}(\mathrm{acac})_{2}$ and $\mathrm{Pd}(\mathrm{acac})_{2}$ are quite uniform in size independently of their nature. The Nanoparticle Tracking Analysis (see Fig. 1).

The NTA shows quite complex pattern of aggregation: due to high reflectivity of metal nanoparticles it is possible to see even (a relatively weak) signal from individual particles at about $10 \mathrm{~nm}$ as an individual distribution top. Both smaller, 30-40 nm, medium size 50-70 and relatively big aggregates with the size of about $100 \mathrm{~nm}$ are present. It can, however, be mentioned that no sub-micro size aggregates could be observed, indicating relative stability of the produced particles against aggregation.

The TEM investigation showed in all cases formation of well-defined and rather uniform spherical particles. They were distinctly not aggregated as the TEM images could show (Fig. 2). The size distribution is relatively sharp with the maximum falling into the interval $10-15 \mathrm{~nm}$. The shape of the distribution curve is slightly shifted to lower sizes with a sharper cut-off for the higer ones.
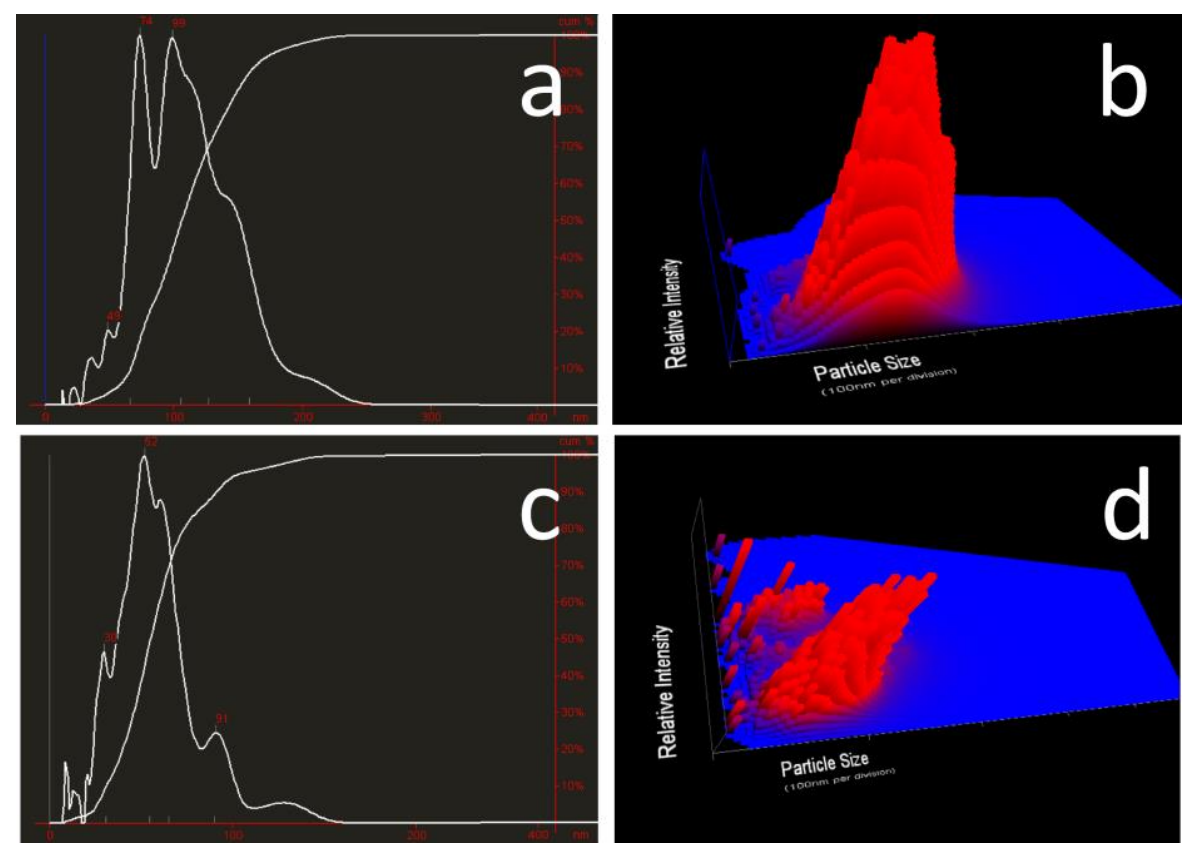

Fig. 1 NTA analysis of the size and luminosity of the nanoparticles produced by solvothermal synthesis from $\mathrm{Ni}(\mathrm{acac})_{2}$ (a and b), and from $\mathrm{Cu}(\mathrm{acac})_{2}$ (c and d) in acetophenone in the presence of 2 equations of $\mathrm{R}^{\mathrm{N}} \mathrm{OH}$ 


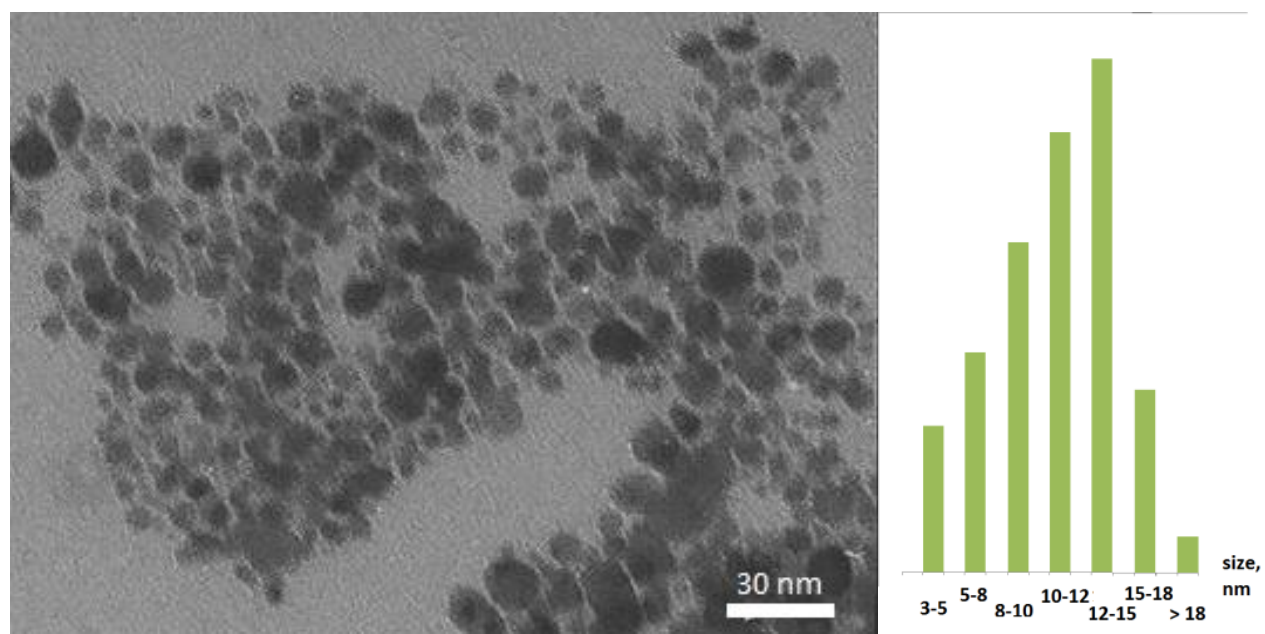

Fig. 2 TEM image of the Ni-Pd alloy nanoparticles - a typical representative of the products produced by Bradley reaction from acac-precursors (peptization of the precipitate phase)

We can clearly from the Fig. 1 see that while $\mathrm{Ni}(\mathrm{acac})_{2}$ in the chosen solvent provides in the presence of reducing agents such as $\mathrm{R}^{\mathrm{N}} \mathrm{OH}$ a single kind of product, the solvothermal treatment of $\mathrm{Cu}(\mathrm{acac})_{2}$, even when aminoalcohol reductant is present, is generating an apparent impurity with the same size and size distribution as the copper metal nanoparticles. We see a fraction with apparently higher luminosity typical for the $\mathrm{Cu}(\mathrm{I})$ oxide $-\mathrm{Cu}_{2} \mathrm{O}$. We have therefore made a thorough investigation of the factors influencing the chemical and phase composition of the nanoparticles produced by this type of synthesis.

\subsection{Factors influencing the chemical and phase composition}

All the syntheses carried out in acetophenone as medium resulted in clear sols with minor amount of precipitate that has been separated by sedimentation. An aliquot of solution was dried in vacuum and both solid materials were investigated by X-ray powder diffraction and SEM-EDS for identification of the produced phases both as obtained and after additional thermal treatment (in order to investigate the stability in air and in some cases to improve crystallinity. The NMR studies revealed in all cases the presence of dehydrogenation products of acetylacetone - the tetraacteyl-ethane, confirming the hypothesis of the beta-hydrogen elimination mechanism as the major pathway of this reaction.

\subsubsection{Influence of the noble metal component}

In the view of attractiveness in the single-synthesis of Pd-doped Ni nanoparticles as a potential alternative to Pd-catalysts for organic synthesis, the solvothermal transformation of solutions containing 10 and $20 \mathrm{~mol} \%$ of palladium respectively was investigated. The results turned to follow a general trend: the precipitate was appreciably enriched in $\mathrm{Pd}$ compared to $\mathrm{Ni}$, while the solution had a ratio affected in the opposite direction. Thus, in the synthesis starting with $10 \% \mathrm{Pd}$ the precipitate contained $44 \% \mathrm{Pd}$ and $56 \% \mathrm{Ni}$, while the solid isolated from solution contained 98 $\% \mathrm{Ni}$ and only $2 \% \mathrm{Pd}$ according to EDS. Both dry phases were gel-like consisting of nanoparticles not distinguishable by the available SEM instrument. The reaction starting from $20 \%$ 


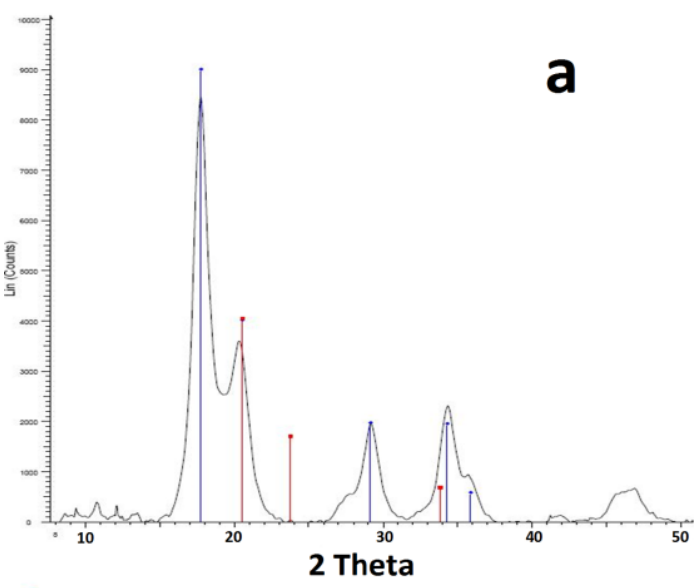

- Ni

- Pd

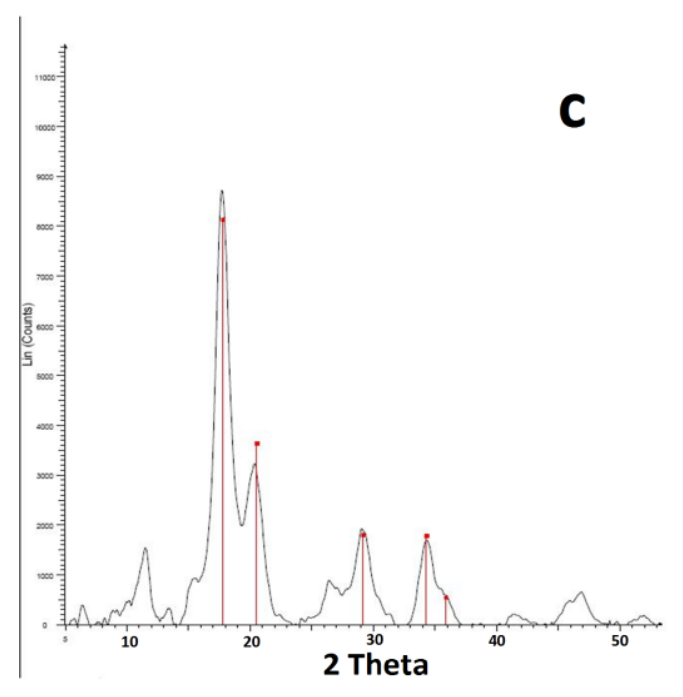

- Pd

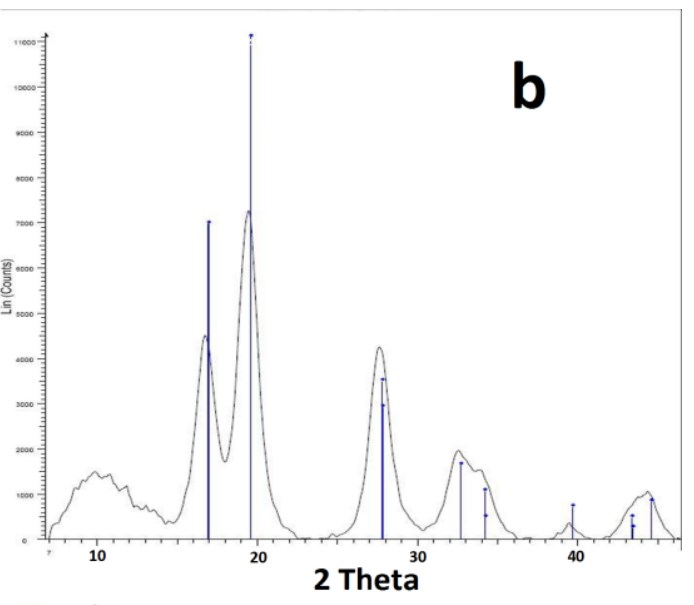

- NiO

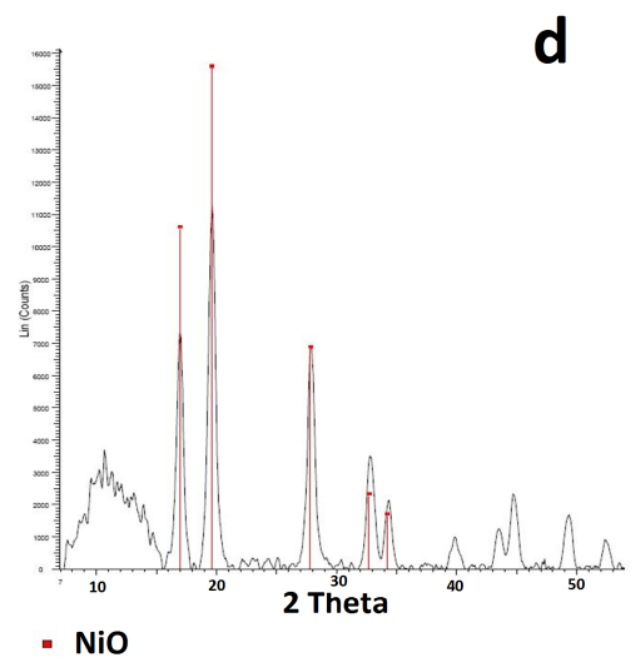

Fig. 3 XRD patterns of the precipitates and solution derived solids from respectively the syntheses starting from $10 \mathrm{~mol} \% \mathrm{Pd}(\mathrm{a}$ and $\mathrm{b}$ ) and $20 \mathrm{~mol} \% \mathrm{Pd}$ (c and d)

Pd gave considerably less shifted element distribution: $74 \% \mathrm{Ni}$ and $26 \% \mathrm{Pd}$ in the precipitate and $95 \%$ of nickel and $5 \%$ of palladium in the solution-derived phase respectively. The phase composition of the precipitate reveals an alloy phase very close to that of the pure palladium metal, while the solid material derived from solution is revealing solely that of the nickel oxide (supposedly, with Pd-doping, see Fig. 3).

As the confirmation of the alloy formation can be provided the fact that oxidation of the precipitates in air at $300^{\circ} \mathrm{C}$ in air yields an apparent mixture of $\mathrm{NiO}$ and $\mathrm{PdO}$ by XRD. It has to be mentioned that the material isolated from solution is apparently not fully crystalline which can be seen from the apparent amorphous halo visible at low angles in the diffraction pattern. 

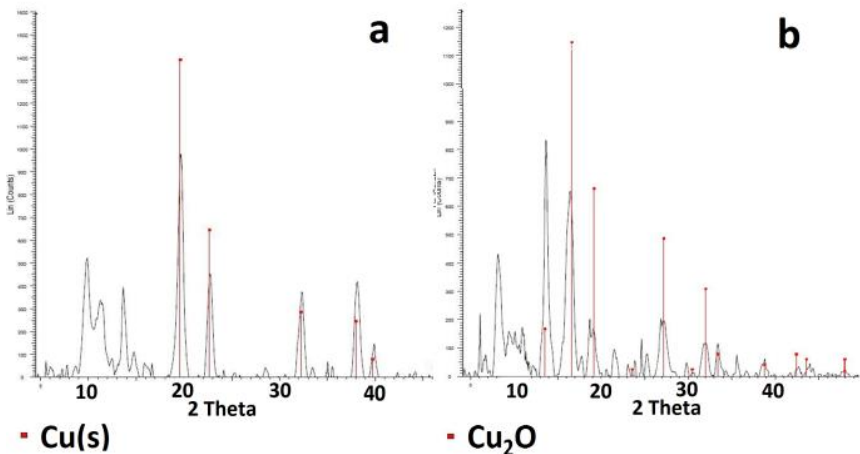

$\cdot \mathrm{Cu}(\mathrm{s})$ $-\mathrm{Cu}_{2} \mathrm{O}$

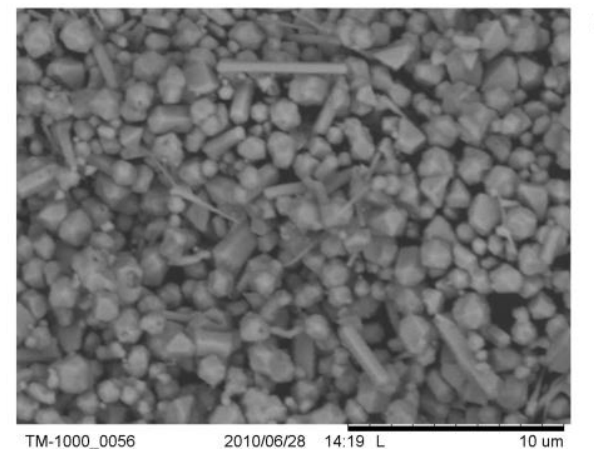

Fig. 4 XRD patterns of the precipitates from the reflux of $\mathrm{Cu}(\mathrm{acac})_{2}$ in acetophenone in $4 \mathrm{~h}$ (a) and $8 \mathrm{~h}$ (b) respectively and the SEM image of the precipitate obtained after $4 \mathrm{~h}(\mathrm{c})$

It has to be noted that the alloy particles are obtained in this case as byproducts with only minor yield.

\subsubsection{Influence of the solvent purity}

The quality of the solvent turned to play major role in the defining the composition of products in case of $\mathrm{Cu}(\mathrm{acac})_{2}$ as precursor. When the freshly received or dried over molecular sieves overnight acetophenone was used for the synthesis in amount of $20 \mathrm{~mL}$ per $0.2 \mathrm{~g}$ of precursor or more, the precipitate phase after $4 \mathrm{~h}$ consisted of submicrometer size metallic copper with welldefined polygonal shape crystals (Fig. 4). Longer refluxing times ( $8 \mathrm{~h}$ or more), considerably bigger amounts of solvent for the same weight of the precursor (over $35 \mathrm{~mL}$ ) and application of the solvent stored without molecular sieves for longer periods produced cupric oxide, $\mathrm{Cu}_{2} \mathrm{O}$ as precipitate. In all cases this material was the major constituent of the particles in solution (yellow to brown color obtained from the original deep green characteristic of the precursor). It can be supposed that the formation of copper metal is hindered by the presence of (excess) of water generated by the crotonic condensation on prolonged reflux or present as an impurity already from the start of the process. Major mechanism of the action of water is apparently microhydrolysis competing with reduction through beta-H-transfer.

The same effect could be observed when using $\mathrm{Ni}\left(\mathrm{OR}^{\mathrm{N}}\right)_{2}$ as precursor (see Fig. 5). In this case the treatment in $4 \mathrm{~h}$ renders crystalline nickel oxide as precipitate and $\mathrm{X}$-ray amorphous Ni metal as the major constituent of the particles in solution. Longer refluxing times, bigger amount of solvent etc. yield $\mathrm{NiO}$ even in solution. 


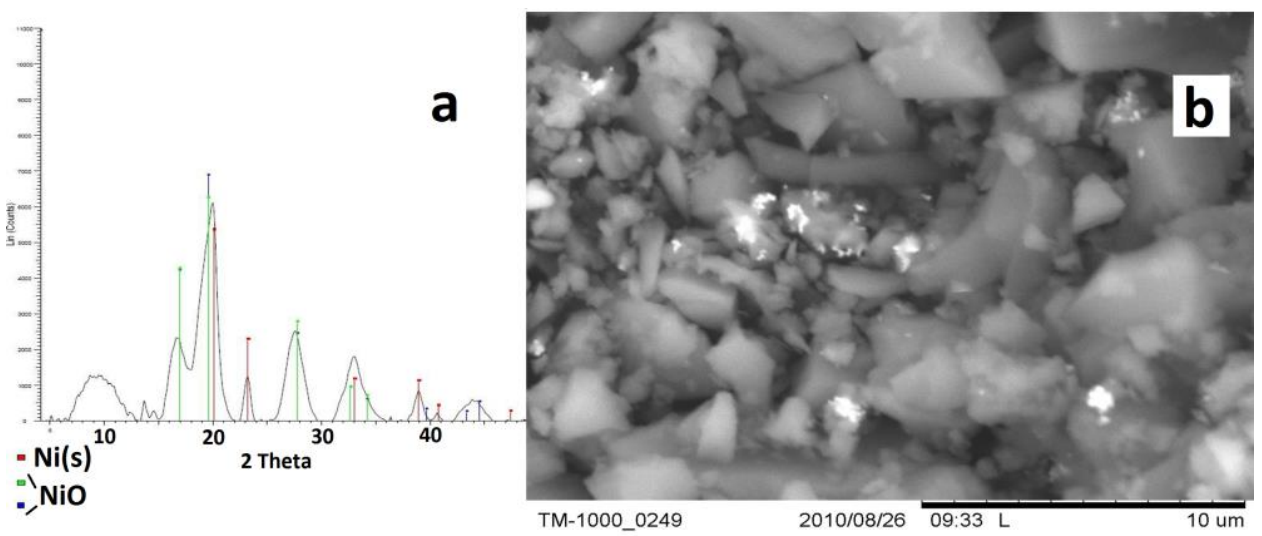

Fig. 5 XRD pattern of the precipitate (a) and the SEM image of the solution derived sample (b) after $4 \mathrm{~h}$ reflux of $\mathrm{Ni}\left(\mathrm{OR}^{\mathrm{N}}\right)_{2}$ in acetophenone

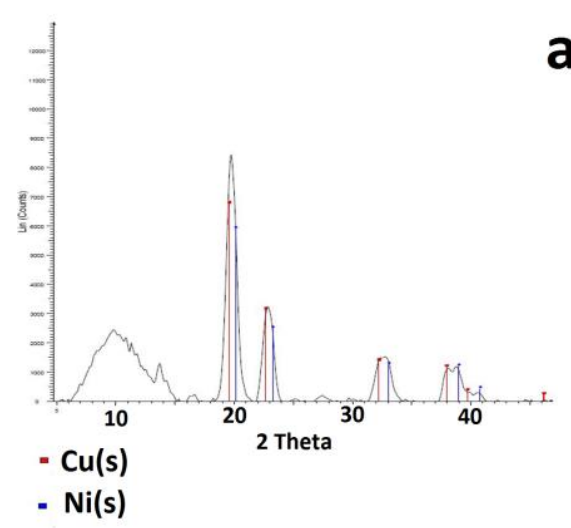

a

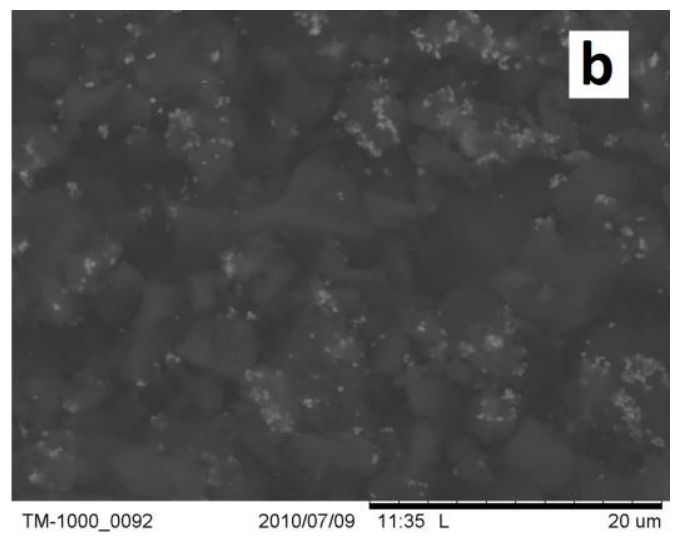

Fig. 6 XRD pattern (a) and the SEM image (b) of the solution derived sample after $4 \mathrm{~h}$ reflux of $\mathrm{Cu}(\mathrm{acac})_{2}$ and $\mathrm{Ni}\left(\mathrm{OR}^{\mathrm{N}}\right)_{2}$ in molar ratio $1: 1$ in acetophenone

\subsubsection{Influence of reducing agents}

As it has been demonstrated above, the presence of reducing ligands in the composition of the $\mathrm{Ni}\left(\mathrm{OR}^{\mathrm{N}}\right)_{2}$ compound was not sufficient to offer pure nickel metal as product. We have then directed the investigation towards two potentially attractive systems - the bimetallic precursor mixture comprising $\mathrm{Cu}(\mathrm{acac})_{2}$ and $\mathrm{Ni}\left(\mathrm{OR}^{\mathrm{N}}\right)_{2}$ in 1:1 ratio, and the simple and complex solutions of metal acetylacetonates in the presence of aminoalcohols such as $\mathrm{R}^{\mathrm{N}} \mathrm{OH}$ and aminoethanol as reductants.

\section{Solvothermal synthesis in the 1:1 mixture of $\mathrm{Cu}(\mathrm{acac})_{2}$ and $\mathrm{Ni}\left(\mathrm{OR}^{\mathrm{N}}\right)_{2}$.}

The analysis of the produced material revealed as well as in the case of Pd and $\mathrm{Ni}$ a shift in composition with the precipitate enriched in more noble metal $(40 \% \mathrm{Ni}$ and $60 \% \mathrm{Cu})$, while the solid obtained by evaporation of the solution was distinctly richer in nickel, the less electropositive element $(87 \% \mathrm{Ni}, 13 \% \mathrm{Cu})$. The precipitate formed after $4 \mathrm{~h}$ of reflux contains metallic phase (see Fig. 6), is pink in color, but on further reflux and even on storage of solutions its color changes to yellow with XRD showing complete transformation into $\mathrm{Cu}_{2} \mathrm{O}$ as the only crystalline 

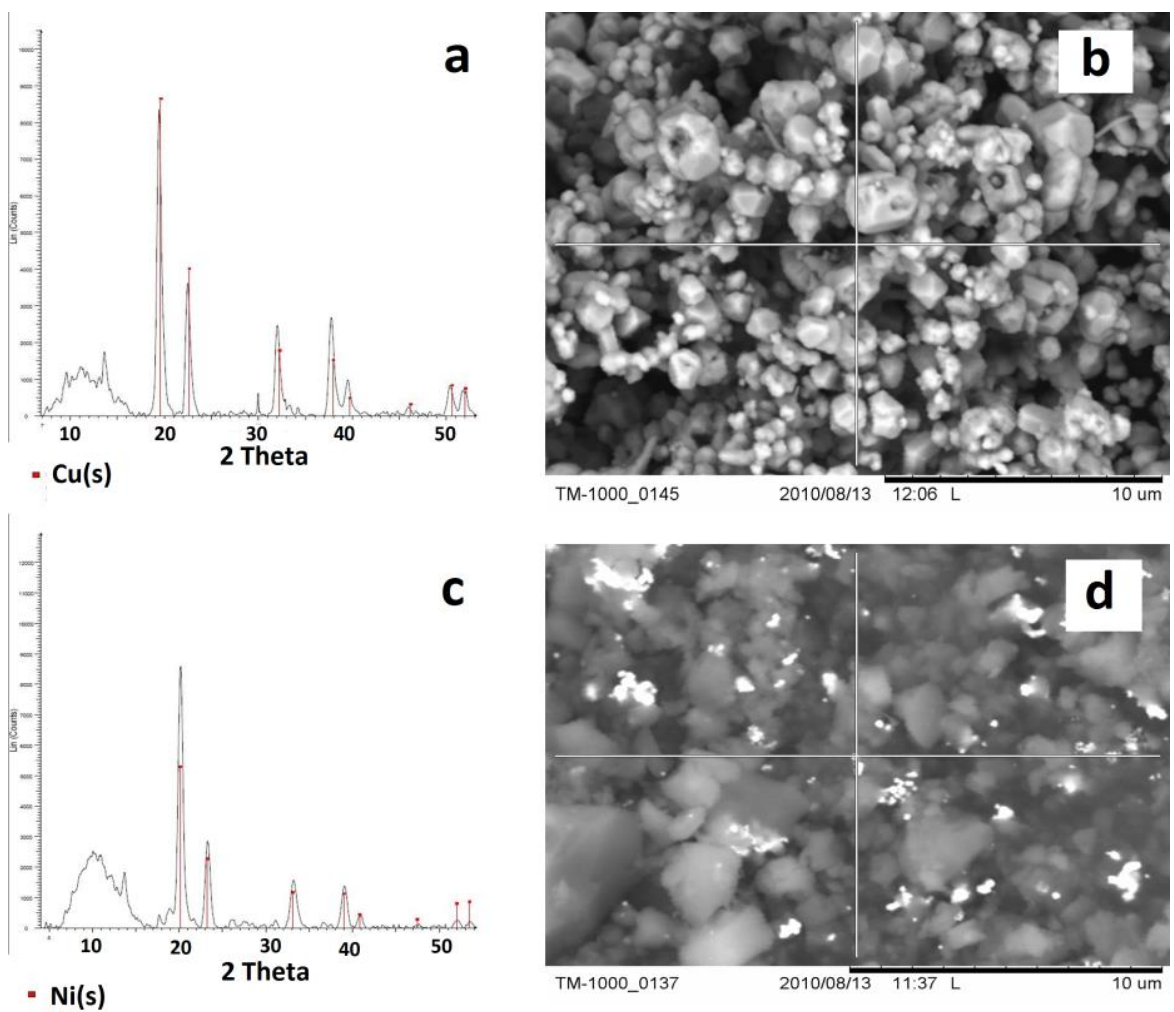

Fig. 7 XRD patterns (a and c) of the solution derived sample after $4 \mathrm{~h}$ reflux of $\mathrm{Cu}(\mathrm{acac})_{2}$ and $\mathrm{Ni}(\mathrm{acac})_{2}$ respectively in acetophenone and the SEM images of the $\mathrm{Cu}$ precipitate and $\mathrm{Ni}$ solution derived material

phase. The material obtained from solution becomes slightly non-uniform on drying with formation of some denser aggregated domains (while NTA and TEM for this material indicate typical patterns for small particles produced by Bradley reaction). The XRD of the phase isolated from solution shows distinct intermediate tops between (otherwise quite related in structure) $\mathrm{Cu}(\mathrm{s})$ and $\mathrm{Ni}(\mathrm{s})$ and can be interpreted as a $\mathrm{Cu}-\mathrm{Ni}$ alloy.

\section{Solvothermal synthesis individual $\mathrm{Ni}$ and $\mathrm{Cu}$ in the presence of aminoalcohols}

The refluxing of $\mathrm{M}(\mathrm{acac})_{2}$ with 2 equations of aminoalcohols in $4 \mathrm{~h}$ appeared to guarantee the complete conversion of both precursors into individual metals. In case of $\mathrm{Cu}(\mathrm{acac})_{2}$ as precursor the precipitate is composed of relatively big, about $1 \mu \mathrm{m}$, polygons, while solution contains uniform $\mathrm{Cu}$ metal particles demonstrated in part 2.1 of the present manuscript. The XRD (Fig. 7) reveals copper metal phase together with some amorphous material, possibly $\mathrm{Cu}_{2} \mathrm{O}$, as indicated by NTA.

In case of $\mathrm{Ni}(\mathrm{acac})_{2}$ as precursor the appearance of both the precipitate and the solid isolated by evaporation of solvent from the liquid reaction medium after $4 \mathrm{~h}$ is essentially the same, showing gel-like aggregates of metal nanoparticles as confirmed by NTA. The XRD is consistent with the metallic Ni. 

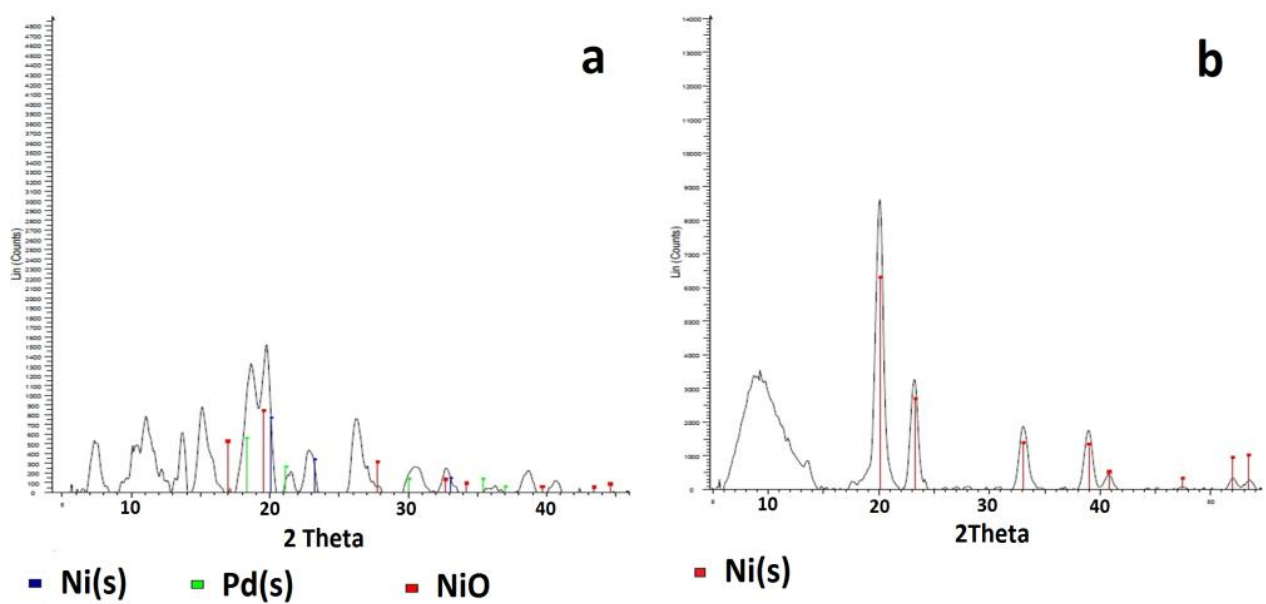

Fig. 8 XRD patterns of the precipitate (a) and the solution derived phase (b) for the sample after $4 \mathrm{~h}$ reflux of $2 \mathrm{~mol} \% \mathrm{Pd}(\mathrm{acac})_{2}$ with $\mathrm{Ni}(\mathrm{acac})_{2}$ and 2 equations $\mathrm{HOR}^{\mathrm{N}}$ in acetophenone

\section{Solvothermal synthesis of the Cu-Ni alloy}

The solvothermal reaction starting from $\mathrm{Cu}$ and $\mathrm{Ni}$ acetylacetonates in the presence of 1-2 equivalents of aminoalcohols results in materials with closely analogous XRD patterns, indicating formation of a copper-nickel alloy but quite shifted compositions according to EDS. The precipitate is composed of $11 \%$ of nickel and $89 \%$ of copper and the mother liquor is composed of $86 \%$ of nickel metal and $14 \%$ of copper metal.

\section{Solvothermal synthesis of the Pd-Ni alloy}

The synthesis using $2 \mathrm{~mol} \%$ of $\mathrm{Pd}(\mathrm{acac})_{2}$ in $\mathrm{Ni}(\mathrm{acac})_{2}$ together with 2 equations of aminoalcohols resulted in truly minor amount of precipitate, possessing relatively complex phase composition (both metals and nickel oxide were present together), while the solution derived material revealed metallic nickel related phase (supposedly Pd-doped) and some amount of amorphous matter (Fig. 8). The elemental analysis shows that the precipitate is composed of $87,3 \%$ of nickel and $12,7 \%$ of palladium and the mother liquor of $98,8 \%$ of nickel and $1,2 \%$ of palladium. It can be concluded that the solution composition was largely reflecting that of the precursorsystem, offering a promising approach to Pd-doped nickel metal particles.

\section{Conclusions}

An attractive approach to small metal nanoparticles derived from late transition metals in a polar high-boiling point solvent such as acetophenone with and without reducing agents has been proposed in this study.

- Metal particles appear generally to require addition of reductants such as aminoalcohols.

- Particles uniform in size and easily dispersible in different media have been obtained as demonstrated by TEM and NTA.

- The effects of the presence of a noble metal precursor, solution purity and the reducing agent have been investigated in detail. 


\section{Acknowledgments}

The research described in this paper was financially supported by the Swedish Research Council project "Molecular Precursors and Molecular Models of Nanoporous Materials". The MCD stay in Sweden was supported by the internship program at ENCCF. The authors express their gratitude to NanoSight Co. UK for the aid with NTA measurements.

\section{References}

Aparna, R., Srinivas, V., Ram, S., de Toro, J.A. and Mizutani, U. (2005), "Structure and magnetic properties of oxygen-stabilized tetragonal Ni nanoparticles prepared by borohydride reduction method", Phys. Rev. $B, 71,184443$.

Chen, C.S., Wu, J.H. and Lai, T.W. (2010), "Carbon dioxide hydrogenation on Cu nanoparticles”, J. Phys. Chem. C, 114, 15021-15028.

Crooks, R.M., Zhao, M.Q., Sun, L., Chechik, V. and Yeung, L.K. (2001), "Dendrimer-encapsulated metal nanoparticles: synthesis, characterization, and applications to catalysis", Acc. Chem. Res., 34, 181-190.

Filipe, V., Hawe, A. and Jiskoot, W. (2010), "Critical evaluation of Nanoparticle Tracking Analysis (NTA) by nanosight for the measurement of nanoparticles and protein aggregates", Pharm. Res., 27, 796-810.

Füldner, S., Mild, R., Siegmund, H.I., Schroeder, J.A., Gruber, M. and König, B. (2010), "Green-light photocatalytic reduction using dye-sensitized TiO2 and transition metal nanoparticles", Green Chem., 12, 400-406.

Hou, Y., Kondoh, H., Ohta, T. and Gao, S. (2005), "Size-controlled synthesis of nickel nanoparticles", Appl. Surf. Sci., 241, 218-222.

Kowlgi, K.N.K., Koper, G.J.M., Picken, S.J., Lafont, U., Zhang, L. and Norder, B. (2011), "Synthesis of Magnetic Noble Metal (Nano) Particles”, Langmuir, 27, 7783-7787.

Metin, Ö., Mazumder, V., Özkar, S. and Sun, S.H. (2010), "Monodisperse nickel nanoparticles and their catalysis in hydrolytic dehydrogenation of ammonia borane", J. Am. Chem. Soc., 132, 1468-1469.

Moreno-Mañas, M. and Pleixats, R. (2003), "Formation of carbon-carbon bonds under catalysis by Transition-Metal Nanoparticles", Acc. Chem. Res., 36, 638-643.

Narayanan, R. and El-Sayed, M.A. (2005), "Catalysis with transition metal nanoparticles in colloidal solution: nanoparticle shape dependence and stability", J. Phys. Chem. B, 109, 12663-12676.

Nikonova, O., Nedelec, J.M., Kessler, V.G. and Seisenbaeva, G.A. (2011), "Precursor-directed assembly of complex oxide nanobeads. The role of strongly coordinated inorganic anions", Langmuir, 27, 1162211628.

Pazik, R., Andersson, R., Kepinski, L., Kessler, V.G., Nedelec, J.M. and Seisenbaeva, G.A. (2011), "Surface functionalization of metal oxide nanoparticles with biologically active molecules containing phosphonate moieties", J. Phys. Chem. C, 115, 9850-9860.

Pązik, R., Piasecka, E., Małecka, M., Kessler, V.G., Idzikowski, B., Śniadecki, Z. and Wiglusz, R.J. (2013), "Facile non-hydrolytic synthesis of highly water dispersible, surfactant free nanoparticles of synthetic $\mathrm{MFe}_{2} \mathrm{O}_{4}\left(\mathrm{M}-\mathrm{Mn}^{2+}, \mathrm{Fe}^{2+}, \mathrm{Co}^{2+}, \mathrm{Ni}^{2+}\right)$ ferrite spinel by a modified Bradley reaction", $R S C$ Adv., 3, 1223012243.

Pazik, R., Tekoriute, R., Håkansson, S., Wiglusz, R., Strek, W., Siesenbaeva, G.A., Gun'ko, Y.K. and Kessler, V.G. (2009), "Precursor and solvent effects in the non-hydrolytic synthesis of complex oxide nanoparticles for bio-imaging applications by the ether elimination (Bradley) reaction", Chem. Eur. J., 15, 6820-6826.

Qi, L.M., Ma, J.M. and Shen, J.L. (1997), "Synthesis of copper nanoparticles in nonionic water-in-oil microemulsions", J. Colloid Interface Sci., 186, 498-500.

Robinson, I., Volk, M., Tung, L.D., Caruntu, G., Kay, N. and Thanh, N.T.K. (2009), "Synthesis of Co nanoparticles by pulsed laser irradiation of cobalt carbonyl in organic solution", J. Phys. Chem. C, 113, 
9497-9501.

Robinson, I., Zacchini, S., Tung, L.D., Maenosono, S. and Thanh N.T.K. (2009), "Synthesis and characterization of magnetic nanoalloys from bimetallic carbonyl clusters", Chem. Mater., 21, 3021-3026.

Roucoux, A., Schulz, J. and Patin, H. (2002), "Reduced transition metal colloids: a novel family of reusable catalysts?", Chem. Rev., 102, 3757-3778.

Schaadt, D.M., Feng, B. and Yu, E.T. (2005), "Enhanced semiconductor optical absorption via surface plasmon excitation in metal nanoparticles", Appl. Phys. Lett., 86, 063106.

Shin, N.C., Lee, Y.H., Shin, Y.H., Kim, J., and Lee, Y.W. (2010), "Synthesis of cobalt nanoparticles in supercritical methanol", Mater. Chem. Phys., 124, 140-144.

Werndrup, P., Kessler, V.G., Gohil, S., Kritikos, M. and Hubert-Pfalzgraf, L.G. (2001), "Isolation and X-ray single crystal study of volatile homo- and heterometallic aminoalkxide complexes of nickel(II): $\mathrm{Ni}\left(\mu_{2^{-}}\right.$ $\left.\mathrm{OR}^{\mathrm{N}}\right)_{2}, \quad \mathrm{Ni}\left(\mu_{2}-\mathrm{OR}^{\mathrm{N}}\right)_{2} \mathrm{C}_{7} \mathrm{H}_{8}$ and $\mathrm{Ni}\left(\mathrm{Ni}_{0.25} \mathrm{Cu}_{0.75}\right)_{2}\left(\mu_{3}-\mathrm{OH}\right)\left(\mu_{2}-\mathrm{OAc}\right)(\mathrm{OAc})_{2}\left(\mu_{2}, \eta_{2}-\mathrm{OR}^{\mathrm{N}}\right)_{3}\left(\mu_{2}-\mathrm{R}^{\mathrm{N}} \mathrm{OH}\right), \quad \mathrm{R}^{\mathrm{N}}=$ $\mathrm{CHMeCH}_{2} \mathrm{NMe}_{2}$ ", Polyhedron, 20, 2163-2169.

Wilkinson, K., Palmberg, L., Kupczyk, M., Fadeel, B., Gerde P., Seisenbaeva, G.A., Dahlen, S.E. and Kessler V.G. (2011), "Solution engineered Pd nanoparticles: models for health effect studies of automotive particulate polution", ACS Nano, 5, 5312-5324.

$C C$ 